\title{
Epoxidation of cyclooctene and cyclohexene with hydrogen peroxide catalyzed by bis[3,5-bis(trifluoromethyl)-diphenyl] diselenide: Recyclable catalytic phases through the use of glycerol-derived solvents
}

\author{
Héctor García-Marín, ${ }^{\mathrm{a}}$ John C. van der Toorn, ${ }^{\mathrm{b}}$ José A. Mayoral, ${ }^{\mathrm{a}, \mathrm{c}} \mathrm{José}_{\mathrm{I}}$. García, ${ }^{* \mathrm{a}}$ and \\ Isabel W. C. E. Arends*b \\ ${ }^{a}$ Dept. Organic Chemistry, Instituto de Ciencia de Materiales de Aragón, Facultad de Ciencias, Univ. de Zaragoza- \\ CSIC, Pedro Cerbuna, 12, E-50009 Zaragoza, Spain. Fax:+34 976762077; Tel: +34 976762271; E-mail: \\ jig@unizar.es \\ ${ }^{b}$ Laboratory for Biocatalysis and Organic Chemistry, Delft University of Technology, Julianalaan 13,. 2628 BL \\ Delft. Netherlands. Fax: +31 15 2784700; Tel: +31 15 2784423; E-mail: I.W.C.E.Arends@tudelft.nl
}

${ }^{c}$ Instituto Universitario de Catálisis Homogénea, Facultad de Ciencias, Univ. de Zaragoza, Pedro Cerbuna, 12, E50009 Zaragoza, Spain. Fax: 976762077; Tel: 976762077; E-mail: mayoral@unizar.es.

\section{ABSTRACT}

A green strategy has been explored for olefin epoxidation which combines renewable solvents (derived from glycerol), aqueous hydrogen peroxide, and catalyst recycling (a seleninic acid derivative). The use of fluorinated glycerol derivatives allows good catalytic activity in the epoxidation of cyclooctene and cyclohexene with aqueous hydrogen peroxide, preventing epoxide hydrolysis to a great extent, which is particularly remarkable in the case of cyclohexene. Furthermore, recycling of the catalytically active phase is possible through distillation of the cyclohexene oxide from the reaction mixture, which can be subsequently recharged with fresh oxidant and substrate.

\section{KEYWORDS}

Hydrogen Peroxide Epoxidation - Glycerol - Selenium catalyst - Catalyst Recycling - Green solvents

\section{Introduction}

Olefin epoxidation is a key transformation in organic synthesis both on a laboratory and on industrial scale, due to the interest of epoxides in the production of chemicals and fine chemicals [1]. The use of hydrogen peroxide for selective epoxidations is highly desirable because it is cheap, the active oxygen content is high, and it is clean, since the only byproduct formed is water [2]. Many catalytic systems based on different metals have been reported for the epoxidation of a wide range of alkenes using hydrogen peroxide [3-5].

Peroxyseleninic acids were first used as stoichiometric oxidants [6], but following the discovery by Sharpless [7] that tert-butyl hydroperoxide can be used in conjunction with catalytic amounts of those selenium derivatives, the method gained interest [8]. Further improvements came with the use of hydrogen peroxide instead of tert-butyl hydroperoxide as the oxidant and the heterogenisation [9-10] and functionalisation of the aromatic ring of the selenium catalyst with the electron withdrawing nitro-substituents [11-13].

Applications of selenium reagents in organic chemistry have developed rapidly over the past years, and comprehensive reviews on this area have appeared [14-20]. Moreover diselenides can be easily oxidized in situ by hydrogen peroxide to seleninic acid or peroxyseleninic acid, which are in some cases excellent catalysts in the oxidation of organic compounds [21-24], as, for instance, epoxidation reaction of alkenes [25], Baeyer-Villiger reaction [26], oxidation of 
carbonyl compounds [27], dehydrogenation of carbonyl compounds [28-29], oxidation of secondary amines [30-31], oxidation of imines [32], or selenenylations or halogenations [33].

But there are other many applications for selenium, for instance organoselenium ligands have been used for metal-catalyzed processes [34], it has been recently included in polyoxometalates to generate a new active catalyst for the epoxidation of olefins [35], or some selenium derivatives have potential as efficient mimetics for selenoenzymes [36].

The efficiency of any catalytic reaction can be further improved by catalyst recycling, which is usually accomplished by using solid heterogeneous catalysts. However, the use of classical heterogeneous catalysts (for instance, those based on titanium) together with aqueous hydrogen peroxide often results in extensive epoxide hydrolysis, and many efforts have been devoted to the synthesis of heterogeneous solid catalysts with hydrophobic properties [37-42]. More recently, the use of polyoxometalates and analogous systems has emerged as an interesting alternative $[3,43]$.

Another alternative would be the use of homogeneous catalysts in a specially designed liquid phase which should be tuned in such a way that easy separation of reagents and products from the catalytic phase should become more straightforward [44]. The catalytically active phase could thus be reused for more reaction cycles. Very often, recovery is accomplished by extraction with an immiscible solvent [45]. Another attractive way is to distil out reagents and products from that liquid phase which contains the catalyst. This strategy has been described for other reactions in the case of ionic liquids [46], but to the best of our knowledge it has not been applied to oxidation reactions yet.

We have recently described the synthesis and characterization of a family of glycerolderived solvents [47]. These solvents present some new and attractive advantages, as there are made from a renewable source, they are (presumably) low toxic, exhibit a low volatility, and possess tuneable physico-chemical properties. We have previously described the use of some of these glycerol-derived solvents in the homogeneously catalyzed epoxidation reaction of cyclooctene, using aqueous hydrogen peroxide as oxidant and bis[3,5bis(trifluoro-methyl)diphenyl] diselenide as catalyst precursor [48].

Although classically this catalytic system had been dominated by the use of dichloromethane (DCM) and 2,2,2-trifluoroethanol (TFE) as solvents [25-26], it was found that some of the glycerol-derived solvents are as good as TFE in some cases and often better than DCM. The best glycerol-based solvents in this study are all bore short fluorinated chains, see scheme 1 . The beneficial effect of trifluoroethanol as a solvent besides being a polar, non-coordinating, non-basic and stable solvent- has been ascribed to its activating properties towards $\mathrm{HOOH}$. Hydrogen peroxide becomes a better nucleophile through exceptional $\mathrm{H}$-bond ability of TFE [49-52]. It can be assumed that this effect can also partially take place for some of our fluorinated glycerol-based solvents.

\section{- Scheme 1 near here -}

In this paper we explore the possibility of combining the advantages of using hydrogen peroxide, an homogeneous catalyst (namely an arylseleninic acid) [21,28,53,54], and solvents from renewable sources (glycerol-derived solvents), with tailored properties, to extend the range of applicability of these catalytic systems to the epoxidation of a more challenging substrate, such as cyclohexene, as well as to have a proof-of-principle for recyclable catalytic liquid phases with our innovative solvents (Scheme 2).

$$
\text { - Scheme } 2 \text { near here - }
$$

\section{Experimental}




\subsection{Materials and Equipment}

\subsubsection{Materials}

Cyclohexene (99\%, Sigma-Aldrich 29240), cyclooctene, (90\%, Fluka 29650), 1,2dimethoxyehane (99,5\%, Sigma-Aldrich 259527), manganese dioxide (Sigma M3138), sodium sulfate (Scharlau SO0664) and hydrogen peroxide (Scharlab HI0139) are commercially available. Common solvents as 2,2,2-trifluoroethanol (99\%, ABCR AB102852), dichloromethane (99,9\% Scharlau CL0348) and $n$-butanol (99,4\%, Sigma-Aldrich 360465), are also commercially available.

Glycerol-based solvents were obtained by ring opening of either the appropriate glycidol ether (non-symmetric glycerol based solvents) or epichlorohydrin (symmetric glycerolbased solvents) with corresponding alkoxide in alcoholic media, as previously described [47], and were purified by vacuum distillation.

The catalyst bis[3,5-bis(trifluoro-methyl)diphenyl] diselenide was obtained as described in the literature [55].

\subsubsection{Equipment}

Reactions were followed by gas chromatography in an Agilent 6890 apparatus equipped with an automatic injector and a FID detector. Two different experimental conditions, shown in Supplementary material, were necessary to use to analyze both olefins. Olefin conversion and olefin oxide yield were determined by area integration of gas chromatography peaks, following calibration equations carried out with ethylene glycol dimethyl ether (glyme) as an internal standard.

\subsection{Oxidation reactions}

The general procedure to the epoxidation of alkenes was carried out at $25^{\circ} \mathrm{C}$, using the following conditions: $0.8-1.0 \mathrm{~mol} \%$ of bis[3,5-bis(trifluoro-methyl)diphenyl] diselenide was dissolved in $2 \mathrm{~mL}$ of solvent. Next, the hydrogen peroxide $(50 \%)$ was added. When the solution became colourless, $2 \mathrm{mmol}$ of ethylene glycol dimethyl ether was added (internal standard) followed by $4 \mathrm{mmol}$ of each olefin. Reactions were followed by taking samples at regular times. Those samples were dissolved in ethyl acetate; some manganese dioxide was added to quench the excess of hydrogen peroxide in the sample. Samples were dried over sodium sulfate and analyzed by GC.

\subsection{Recycling experiments}

After certain reaction times (see Tables 1 and 4) the epoxidation product was distilled off during $1-2 \mathrm{~h}$ at $50{ }^{\circ} \mathrm{C}$ and 10 mbar. Then more hydrogen peroxide was added to the remained distillation mixture (solvent and catalyst). After a few minutes more olefin was added. Reactions were followed by GC as was previously described.

\subsection{Safety concerning}

The distillation of systems containing $\mathrm{H}_{2} \mathrm{O}_{2}$ or other peroxo-species can be dangerous 
since it can be formed exploding compounds. Moreover, severe safety measures should be taken when the distillation implies high temperatures, large volumes of peroxides or solvents with low flash point.

\subsection{Stability of solvents}

In no case by-products coming from solvent oxidation in the reaction conditions were found. Furthermore, neither peroxide compounds nor by-products from decomposition were observed when solvents were put under 50 bar $\mathrm{O}_{2}(8 \%)$ at $100{ }^{\circ} \mathrm{C}$ for 4 hours. These results indicate the remarkable stability of the solvents employed under oxidation conditions, even though most of them being secondary alcohols.

\section{Results and Discussion}

In the preliminary studies of the epoxidation of cyclooctene using diselenide $\mathbf{1}$ as precatalyst and $\mathrm{H}_{2} \mathrm{O}_{2}$ as oxidant in different reaction media, solvent properties effects were investigated through QSPR equations relating solvent polarity and hydrophobicity parameters with catalytic activity [48]. Following the conclusions of this study we have chosen three common organic solvents and three glycerol derivatives as representative sample of solvents among those in which the catalytic reaction takes place. The set of solvents used is the following: from the common organic solvents 2,2,2-trifluoroethanol (TFE), dichloromethane (DCM) and $n$-butanol $(n-\mathrm{BuOH})$, from the glycerol-derived solvents 1,3-di-n-butoxy-2-propanol (404), 1,3-bis(2,2,2-trifluoroethoxy)-2-propanol (3F03F), 1,3-bis(2,2,3,3,3-pentafluoro- $n$-prop-oxy)-2-propanol $(5 \mathrm{~F} 05 \mathrm{~F})$ and 2 -methoxy1,3-bis(2,2,2-trifluoroethoxy)propane (3F13F).

Initial turnover frequencies $\left(\mathrm{TOF}_{0}\right)$ and total alkene conversions at different reaction times have been determined for each reaction carried out in the corresponding solvent.

\subsection{Epoxidation of cyclooctene}

Epoxidation of cyclooctene was carried out using the seven above-mentioned solvents. Good conversions and selectivities were obtained with most solvents tested (Table 1). In no case reaction other by-products than cyclooctan-1,2-diol were observed. It can be seen that there is a direct relation between polarity of the solvent and the reaction kinetics of the epoxidation reaction. Using data in Table 1, the following regression equation can be established:

$$
\text { TOF }_{0}=591.6 \cdot E_{T}^{N}-263.3 \cdot \beta-43.2 \quad N=7 ; R^{2}=0.970 ; s=30.3
$$

In line with our previous QSPR results [48], the hydrogen bond ability of the solvent is the main feature influencing the catalytic activity. Best solvents have to possess good hydrogen bond donor (high $\mathrm{E}_{\mathrm{T}}^{\mathrm{N}}$ ) and reduced hydrogen bond acceptor (low $\beta$ ) abilities. These results agree with the activation of hydrogen peroxide by multiple hydrogen-bond networks, demonstrated by Berkessel et al. in a series of elegant experimental and computational works $[50,51,56]$.

The two best-performing catalytic phases, namely those with TFE and 3F03F as 
solvents, were recharged with fresh hydrogen peroxide and cyclooctene, without any further reaction treatment, in order to continue the reaction. The catalyst remained fully active and the reaction could take place for up to eleven recharges without loss of activity (Fig. 1).

$$
\text { - Figure } 1 \text { near here - }
$$

Table 2 summarizes the accumulated turnover numbers (TON) after each recharging cycle. As can be seen, the catalytic activity is maintained throughout the recharging steps and the TON increase is almost constant for both solvents. Epoxidation of cyclooctene in $3 \mathrm{~F} 03 \mathrm{~F}$ is somewhat slower than in TFE (see $\mathrm{TOF}_{0}$ in Table 1), so whereas almost total cyclooctene conversion is achieved after $2 \mathrm{~h}$ of reaction time in TFE, some unreacted cyclooctene remains in the reaction medium after each step (Fig. 1b). In all cases there was full selectivity towards cyclooctene oxide as the sole product. These results point to the stability of the catalytic system in the reaction conditions, which opens the possibility of recovery and recycling of the catalytically active phase.

As the boiling point of TFE $\left(79^{\circ} \mathrm{C}\right)$ is lower than cyclooctene oxide $\left(189^{\circ} \mathrm{C}\right)$, the direct distillation of the product from the reaction medium is impossible, which prevents the option of recovery of the catalytic solution. On the other hand, when $3 \mathrm{~F} 03 \mathrm{~F}\left(197^{\circ} \mathrm{C}\right)$ is used as solvent in this reaction the distillation of the cyclooctene oxide from the reaction should in principle be possible.

After the distillation of the epoxide, by high vacuum at low temperature, it turned out that the catalyst was slightly deactivated (Table 3); moreover the total separation of cyclooctene oxide from 3F03F was impossible by fractional distillation, and some solvent (30-40\%) was lost after each recovery cycle.

$$
\text { - Table } 3 \text { near here - }
$$

Therefore it seemed logical to explore this strategy using a more volatile epoxide which should solve the fractional distillation issue. To test this hypothesis we chose cyclohexene for the recycling experiments. Furthermore cyclohexene is far more sensitive to hydrolysis than cyclooctene, and hence this substrate constitutes a more valuable test regarding catalyst application scope.

\subsection{Epoxidation of cyclohexene}

Epoxidation of cyclohexene was carried out using six of the seven solvents employed in the cyclooctene epoxidation experiments $(5 \mathrm{~F} 05 \mathrm{~F}$ was excluded because it has almost the same properties as $3 \mathrm{~F} 03 \mathrm{~F})$. Although good conversions and selectivities were obtained in relatively short reaction times, after some time the epoxide started to decompose slowly and the selectivity of the reaction decreased (Table 4).

\footnotetext{
- Table 4 near here -
}

Fig. 2 shows the evolution of epoxide yield with time in each solvent tested, without sodium acetate added, where the cyclohexene oxide is not totally stable and it decomposed by hydrolysis. Water miscibility seemed to be the key point controlling the reaction course. A low miscibility of water with the solvent slows the reaction by reducing the concentration of water in the active phase. Water miscibility depends on both hydrogen bond donor (HBD) ability and lipophilicity of the solvent. In this regard, it is worth noting that $3 \mathrm{~F} 03 \mathrm{~F}$ gathers both a high HBD ability and immiscibility with water, which results in high conversions, but also high epoxide stability towards hydrolysis. This unusual combination of physico-chemical properties has also recently been reported for other fluorinated derivatives of glycerol [47], and it allows the development of special applications in 
catalytic systems, unreachable for common organic solvents. One of these applications has been recently reported by our group [55].

The reaction was also carried out in the presence of traces of sodium acetate $(0.5 \mathrm{~mol} \%)$ to control the $\mathrm{pH}$ of the reaction medium and to minimize the hydrolysis suffered by the epoxide [25-27], which can be observed in entries 7 and 8 of Table 4. Although the reaction is slightly slower in these conditions, the hydrolysis was totally avoided.

$$
\text { - Figure } 2 \text { near here - }
$$

Similar to the case of cyclooctene, it was not possible to distil directly the oxide product from the reaction media when 2,2,2-trifluoroethanol was used, because the boiling point of TFE $\left(79^{\circ} \mathrm{C}\right)$ is lower than that of cyclohexene oxide $\left(129^{\circ} \mathrm{C}\right)$. However, when 3F03F (197 ${ }^{\circ} \mathrm{C}$ ) was used as solvent, the fractional distillation of the cyclohexene oxide from the reaction was possible (recovering $\mathrm{ca}$. $80 \%$ of the produced epoxide) with no loss of solvent after each distillation. Unfortunately, we found that after every separation the epoxide from the catalytically active phase, by a low temperature distillation, the catalyst was progressively deactivated (Table 5).

\section{- Table 5 near here -}

We observed during low temperature vacuum distillation that the remaining hydrogen peroxide was deteriorating the catalyst. This deactivation is not merely due to the presence of an excess of hydrogen peroxide, since recharging experiments had already demonstrated catalyst stability under reaction conditions, and independent experiments showed that is necessary to heat the catalyst solution at $80{ }^{\circ} \mathrm{C}$ for three or more hours in the presence of hydrogen peroxide to induce phase deactivation. To avoid the deactivation during recovery processes, the reaction was carried out with a sub-stoichiometric amount of oxidant. Although this obviously results in lower and slower olefin conversion (Table 6), the stability of catalyst and product is higher under distillation conditions, which allows catalyst and solvent recovery by direct distillation of the cyclohexene oxide and the unreacted cyclohexene.

$$
\text { - Table } 6 \text { near here - }
$$

By working at low cyclohexene conversions, three catalytic cycles were carried out, see Table 7, complete recovery of the catalytic medium (catalyst and the glycerol-derived solvent, 3F03F) was possible (see Fig. 3) and only in the third catalytic cycle a small amount of cyclohexan-1,2-diol was observed, although cyclohexene oxide could be easily isolated in pure form by distillation.

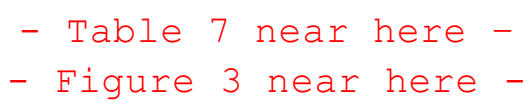

\section{Conclusions}

An efficient strategy for olefin epoxidation, combining renewable solvents (derived from glycerol), a green oxidant (aqueous hydrogen peroxide), and catalyst recycling (an arylseleninic acid) has been explored. The use of fluorinated glycerol derivatives allows good catalytic activity in the epoxidation of cyclooctene and cyclohexene with aqueous hydrogen peroxide, preventing epoxide hydrolysis, which is particularly remarkable in the case of cyclohexene. Results were in some cases comparable to using standard organic solvents and even better in most cases.

Catalyst stability tests show that the catalytic medium (solvent + seleninic acid derivative) can be repeatedly recharged with reactants without loss of catalytic activity and 
selectivity. Optimization of the reaction conditions results in the preparation of a recoverable catalytic phase allowing direct distillation of the epoxide product (cyclohexene oxide), with further recycling and reuse of the solvent and the catalyst. This recovery strategy could, in principle, be extrapolated to other catalytic transformations carried out in these kinds of green solvents.

\section{Acknowledgements}

Financial support from the European Union (project Solvsafe, NMP2-CT-2005-011774 and the European Social Fund), the Spanish MCIMM (projects CTQ2008-05138 and Consolider Ingenio 2010 CSD 2006-0003) and the Gobierno de Aragón (Grupo de Excelencia E11) is gratefully acknowledged. H. García-Marín thanks the Gobierno de Aragón and Caja de Ahorros de la Inmaculada for grants.

\section{Appendix A. Supplementary data}

Supplementary data associated with this article can be found, in the online version, at doi:10.1016/j.molcata.xxxx.xx.xx

\section{References}

[1] G. Sienel, R. Rieth, K. T. Rowbottom in Ullmann's Encyclopedia of Organic Chemicals. Ed. Wiley-VCH, Weinheim, 1999.

[2] R. A. Sheldon in Topics in Current Chemistry: Homogeneous and Heterogeneous Catalytic Oxidations with Peroxide. Ed. Springer-Verlag, Berlin, 1993.

[3] G. Grigoropoulou, J. H. Clark, J. A. Elings, Green Chem. 5 (2003) 1-7.

[4] D. E. De Vos, B. F. Sels, P. A. Jacobs, Adv. Synth. Catal. 345 (2003) 457-473.

[5] D. E. De Vos, B. F. Sels, P. A. Jacobs, Adv. Catal. 46 (2001) 1-87.

[6] P. A. Grieco, Y. Yokohama, S. Gilman, M. Nishizawa, J. Org. Chem. 42 (1977) 2034-2036.

[7] M. A. Umbreit, K. B. Sharpless, J. Am. Chem. Soc. 99 (1977) 5526-5528.

[8] I. Kuwajima, M. Shimizu, H. Urabe, J. Org. Chem., 47 (1982) 837-842.

[9] R. T. Taylor, L. A. Flood, J. Org. Chem. 48 (1983) 5160-5164.

[10] B. Betzemeier, F. Lhermitte, P. Knochel, Synlett (1999) 489.

[11] T. Hori, K. B. Sharpless, J. Org. Chem. 43 (1978) 1689-1697.

[12] H. J. Reich, F. Chow, S. L. Peake, Synthesis (1978) 299-301.

[13] L. Syper, Synthesis (1989) 167-172.

[14] P. L. Beaulieu, R. Déziel in Organoselenium Chemistry: A Practical Approach. Ed. Oxford University Press, New York, 1999.

[15] T. Wirth, Tetrahedron 55 (1999) 1-28.

[16] T. Wirth, Top. Curr. Chem. 208 (2000) 143-176.

[17] T. Wirth, Angew. Chem. Int. Ed. 39 (2000) 3740-3749.

[18] T. Wirth in Comprehensive Organometallic Chemistry III. Ed. Elsevier, Oxford, 2006.

[19] D. M. Browne, T. Wirth, Curr. Org. Chem. 10 (2006) 1893-1903.

[20] D. M. Freudendahl, S. A. Shahzad, T. Wirth, Eur. J. Org. Chem. (2009) 1649-1664.

[21] J. Mlochowski, M. Brza, M. Giurg, J. Palus, H. Wojtowicz, Eur. J. Org. Chem. (2003) 4329-4339.

[22] J. Mlochowski, M. Brza, M. Chojnacka, M. Giurg, H. Wójtowicz, Arkivoc (2004) 226-248.

[23] D. H. R. Barton, D. J. Lester, S. V. Ley, J. Chem. Soc. Chem. Commun. (1978) 276-277.

[24] D. Zhao, M. Johansson, J. E. Bäckvall, Eur. J. Org. Chem. (2007) 4431-4436.

[25] G. J. ten Brink, B. C. M. Fernandes, M. C. A. Vliet, I. W. C. E. Arends, R. A. Sheldon, J. Chem. Soc. Perkin Trans. 1 (2001) 224-228.

[26] G. J. ten Brink, J. M. Martijn, J. H. Vis, I. W. C. E. Arends, R. A. Sheldon, J. Org. Chem. 66 (2001) 24292433. 
[27] G. J. ten Brink, J. H. Vis, I. W. C. E. Arends, R. A. Sheldon, Tetrahedron 58 (2002) 3977-3983.

[28] H. J. Reich, J. M. Renga, I. L. Reich, J. Am. Chem. Soc. 97 (1975) 5434-5747.

[29] D. Crich, G. R. Barba, Org. Lett. 2 (2000) 989-991.

[30] S. I. Murahashi, T. Shiota, Tetrahedron Lett. 28 (1987) 2383-2386.

[31] B. Priewisch, K. Rück-Braun, J. Org. Chem. 70 (2005) 2350-2352.

[32] B. H. Brodsky, J. Du Bois, J. Am. Chem. Soc. 127 (2005) 15391-15393.

[33] D. M. Freudendahl, S. Santoro, S. A. Shahzad, C. Santi, T. Wirth, Angew. Chem. Int. Ed. 48 (2009) 84098411.

[34] A. L. Braga, D. S. Lüdtke, F. Vargas, R. C. Braga, Synlett (2006) 1453-1466.

[35] K. Kamata, R. Ishimoto, T. Hirano, S. Kuzuya, K. Uehara, N. Mizuno, Inorg. Chem. 49 (2010) 2471-2478.

[36] B. K. Sarma, G. Mugesh, Org. Biomol. Chem. 6 (2008) 965-974.

[37] T. Blasco, M. A. Camblor, A. Corma, P. Esteve, J. M. Guil, A. Martinez, J. A. Perdigon-Melon, S. Valencia, J. Phys. Chem. B, 102 (1998) 75-88.

[38] J. M. Fraile, J. I. Garcia, J. A. Mayoral, E. Vispe, J. Catal. 189 (2000) 40-51.

[39] J. M. Fraile, J. I. Garcia, J. A. Mayoral, E. Vispe, D. R. Brown, M. Naderi, Chem. Commun. (2001) 15101511.

[40] J. M. Fraile, J. I. Garcia, J. A. Mayoral, E. Vispe, J. Catal. 204 (2001) 146-156.

[41] J. M. Fraile, J. I. Garcia, J. A. Mayoral, E. Vispe, Appl. Catal. A, 276 (2004) 113-122.

[42] M. Guidotti, C. Pirovano, N. Ravasio, B. Lazaro, J. M. Fraile, J. A. Mayoral, B. Coqc, A. Galarneau, Green Chem. 11 (2009) 1421-1427.

[43] J. Brégeault, M. Vennat, L. Salles, J. Piquemal, Y. Mahha, E. Briot, P. C. Bakala, A. Atlamsani, R. Thouvenot, J. Mol. Catal. A, 250 (2006) 177-189.

[44] J. Muzart, Adv. Synth. Catal. 348 (2006) 275-295.

[45] See for instance: K. Smith, S. Liu, G. A. El-Hiti, Catal. Lett. 98 (2004) 95-101.

[46] For example: J. Dupont, R. F. de Souza, P. A. Z. Suarez, Chem. Rev. 102 (2002) 3667-3692.

[47] J. I. García, H. García-Marín, J. A. Mayoral, P. Pérez, Green Chem. 12 (2010) 426-434.

[48] H. García-Marín, J. C. van der Toorn, J. A. Mayoral, J. I. García, I. W. C. E. Arends, Green Chem., 11 (2009) $1605-1609$.

[49] J. Bégué, D. Bonnet-Delpon, B. Crousse, Synlett (2004) 18-29.

[50] A. Berkessel, J. A. Adrio, D. Hüttenhain, J. M. Neudörfl, J. Am. Chem. Soc. 128 (2006) 8421-8426.

[51] A. Berkessel, J. A. Adrio, J. Am. Chem. Soc. 128 (2006) 13412-13412.

[52] S. P. de Visser, J. Kaneti, R. Neumann, S. Shaik, J. Org. Chem. 68 (2003) 2903-2912.

[53] L. Syper, J. Mlochowski, Synthesis (1984) 747-751.

[54] L. Syper, J. Mlochowski, Tetrahedron 43 (1987) 207-213.

[55] L. Aldea, J. M. Fraile, H. García-Marín, J. I. García, C. Herrerías, J. A. Mayoral, I. Pérez, Green. Chem., 12 (2010) 435-440.

[56] A. Berkessel, J. A. Adrio, Adv. Synth. Catal. 346 (2004) 275-280. 
TABLES, FIGURES AND SCHEMES

Table 1

Cyclooctene epoxidation results in different solvents.

\begin{tabular}{|c|c|c|c|c|c|c|}
\hline Solvent & $\mathrm{E}_{\mathrm{T}}^{\mathrm{N}}$ & $\beta$ & $\begin{array}{l}\mathrm{TOF}_{0} \\
\left(\mathrm{~h}^{-1}\right)^{\mathrm{a}}\end{array}$ & $\begin{array}{l}\text { Conv. }(\%)^{b} \\
(20 \mathrm{~min})\end{array}$ & $\begin{array}{l}\text { Conv. }(\%)^{b} \\
(120 \mathrm{~min})\end{array}$ & $\begin{array}{l}\text { Select. } \\
(\%)^{\mathrm{c}}\end{array}$ \\
\hline TFE & 0.898 & 0.000 & 491 & 99 & 100 & 97 \\
\hline $\mathrm{TFE}^{\dagger}$ & & & - & 1 & 26 & 91 \\
\hline DCM & 0.309 & 0.000 & 153 & 54 & 93 & 93 \\
\hline $\mathrm{n}-\mathrm{BuOH}$ & 0.586 & 0.880 & 100 & 18 & 59 & 93 \\
\hline $3 \mathrm{~F} 03 \mathrm{~F}$ & 0.701 & 0.700 & 155 & 61 & $>99$ & 99 \\
\hline $5 \mathrm{~F} 05 \mathrm{~F}^{\dagger}$ & & & - & 1 & 1 & - \\
\hline $3 \mathrm{~F} 13 \mathrm{~F}$ & 0.553 & 0.500 & 130 & 48 & 88 & 88 \\
\hline $3 \mathrm{~F} 13 \mathrm{~F}^{\dagger}$ & & & - & 0 & 3 & - \\
\hline 404 & 0.450 & 0.600 & 46 & 16 & 52 & 90 \\
\hline $404^{\dagger}$ & & & - & 0 & 2 & - \\
\hline
\end{tabular}

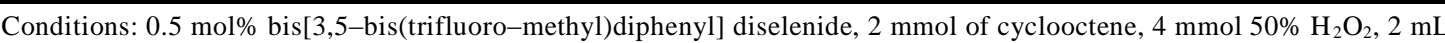
solvent, $25^{\circ} \mathrm{C}, 2 \mathrm{~h}$. ${ }^{\dagger}$ Blank test without catalyst, $2 \mathrm{mmol}$ of cyclooctene, $4 \mathrm{mmol} \mathrm{50 \%} \mathrm{H}_{2} \mathrm{O}_{2}, 2 \mathrm{~mL}$ solvent, $57{ }^{\circ} \mathrm{C}, 2 \mathrm{~h}[25]$ ${ }^{\mathrm{a}} \mathrm{TOF}_{0}\left(\mathrm{~h}^{-1}\right)$, initial rate in $\mathrm{mmol}$ product $\cdot \mathrm{mmol}$ catalyst ${ }^{-1} \cdot \mathrm{h}^{-1} \cdot{ }^{\mathrm{b}} \mathrm{GC}$-conversión, mmol olefin converted $\cdot \mathrm{mmol}^{\mathrm{olefin}}{ }^{-1}$. ${ }^{\mathrm{c}}$ Selectivity, mmol epoxide $\cdot \mathrm{mmol}$ converted olefin ${ }^{-1}$.

Table 2

Total turnover number (TON) after each cycle of oxidant (hydrogen peroxide) and olefin (cyclooctene) recharging.

\begin{tabular}{llll}
\hline TFE & & 3F03F & \\
\hline Step & TON $^{\mathrm{a}}$ & Step & TON $^{\mathrm{a}}$ \\
\hline 1 & 121 & 1 & 118 \\
2 & 242 & 2 & 230 \\
3 & 360 & 3 & 352 \\
4 & 484 & 4 & 471 \\
11 & & $\ldots$ & 1296 \\
\hline
\end{tabular}

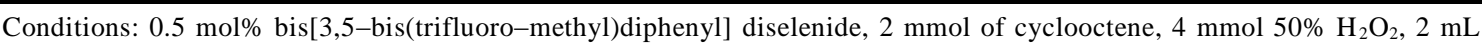
solvent, $25{ }^{\circ} \mathrm{C}, 2 \mathrm{~h}$. After each cycle, $4 \mathrm{mmol} 50 \% \mathrm{H}_{2} \mathrm{O}_{2}$ and $2 \mathrm{mmol}$ of cyclooctene were subsequently added.

${ }^{\mathrm{a}}$ Total turnover number, $\mathrm{mmol}$ epoxide $\cdot \mathrm{mmol}$ catalyst $^{-1}$.

Table 3

Recycling of the catalytic phase by direct distilling of the cyclooctene oxide from the reaction medium, in the case of 3F03F.

\begin{tabular}{lllll}
\hline Solvent & Cycle & $\mathrm{TOF}_{0}\left(\mathrm{~h}^{-1}\right)^{\mathrm{a}}$ & Yield $(\%)^{\mathrm{b}}$ & Isolated $(\%)^{\mathrm{c}, \mathrm{d}}$ \\
\hline 3 F03F & 1 & 160 & 82 & - \\
& 2 & 90 & 85 & - \\
\hline
\end{tabular}

Conditions: $0.5 \mathrm{~mol} \%$ bis[3,5-bis(trifluoro-methyl)diphenyl] diselenide, $2 \mathrm{mmol}$ of cyclooctene, $4 \mathrm{mmol}_{50 \%} \mathrm{H}_{2} \mathrm{O}_{2}, 2 \mathrm{~mL}$ solvent, $25{ }^{\circ} \mathrm{C}, 2 \mathrm{~h}$. After the first cycle, cyclooctene oxide was removed by high vacuum distillation and $4 \mathrm{mmol} 50 \% \mathrm{H}_{2} \mathrm{O}_{2}$ and $2 \mathrm{mmol}$ of cyclooctene were added to run the second cycle.

${ }^{\mathrm{a}} \mathrm{TOF}_{0}\left(\mathrm{~h}^{-1}\right)$, initial rate in $\mathrm{mmol}$ product $\cdot \mathrm{mmol}$ catalyst ${ }^{-1} \cdot \mathrm{h}^{-1}$. ${ }^{\mathrm{b}} \mathrm{CG}$-yield of epoxide, mmol cyclooctene oxide $\mathrm{mmol}$ cyclooctene ${ }^{-1}$. ${ }^{\mathrm{c}}$ Pure cyclooctene oxide obtained, mmol cyclooctene oxide isolated $\cdot \mathrm{mmol}$ cyclooctene oxide ${ }^{-1}$. ${ }^{\mathrm{d}} \mathrm{Cyclooctene}$ oxide was contaminated with traces of solvent (3F03F). 
Table 4

Cyclohexene epoxidation results in different solvents.

\begin{tabular}{llllllll}
\hline Solvent & $\mathrm{E}_{\mathrm{T}}{ }^{\mathrm{N}}$ & $\beta$ & $\mathrm{TOF}_{0}\left(\mathrm{~h}^{-1}\right)^{\mathrm{a}}$ & $\begin{array}{l}\text { Conv. }(\%)^{\mathrm{b}} \\
(20 \mathrm{~min})\end{array}$ & $\begin{array}{l}\text { Select. }(\%)^{\mathrm{c}, \mathrm{d}} \\
(20 \mathrm{~min})\end{array}$ & $\begin{array}{l}\text { Conv. }(\%)^{\mathrm{b}} \\
(120 \mathrm{~min})\end{array}$ & $\begin{array}{l}\text { Select. }(\%)^{\mathrm{c}, \mathrm{d}} \\
(120 \mathrm{~min})\end{array}$ \\
\hline TFE & 0.898 & 0.000 & 398 & 100 & 89 & 100 & 16 \\
DCM & 0.309 & 0.000 & 133 & 39 & 88 & 80 & 75 \\
n-BuOH & 0.586 & 0.880 & 44 & 11 & 95 & 59 & 35 \\
3F03F & 0.701 & 0.700 & 183 & 46 & 86 & 96 & 73 \\
3F13F & 0.553 & 0.500 & 98 & 22 & 70 & 66 & 8 \\
404 & 0.450 & 0.600 & 10 & 11 & 69 & 38 & 70 \\
TFE $^{\dagger}$ & 0.898 & 0.000 & 240 & - & - & 100 & 98 \\
$3 \mathrm{~F}^{*} \mathrm{~F}^{\dagger}$ & 0.701 & 0.700 & 240 & - & - & 95 & 97 \\
\hline
\end{tabular}

Conditions: $0.5 \mathrm{~mol} \%$ bis[3,5-bis(trifluoro-methyl)diphenyl] diselenide, $2 \mathrm{mmol}$ of cyclohexene, $4 \mathrm{mmol} 50 \% \mathrm{H}_{2} \mathrm{O}_{2}, 2 \mathrm{~mL}$ solvent, $25^{\circ} \mathrm{C}, 2 \mathrm{~h} .{ }^{\dagger} 0.5 \mathrm{~mol} \%$ of sodium acetate was added.

${ }^{\mathrm{a}} \mathrm{TOF}_{0}\left(\mathrm{~h}^{-1}\right)$, initial rate in $\mathrm{mmol}$ product $\cdot \mathrm{mmol}$ catalyst $\mathrm{t}^{-1} \cdot \mathrm{h}^{-1} \cdot{ }^{\mathrm{b}} \mathrm{GC}-$ conversión of olefine, mmol cyclohexene converted $\cdot \mathrm{mmol}$ cyclohexene ${ }^{-1}$. ${ }^{\mathrm{c} S e l e c t i v i t y, ~ m m o l ~ c y c l o h e x e n e ~ o x i d e-m m o l ~ c y c l o h e x e n e ~}{ }^{-1}$. ${ }^{\mathrm{d}}$ Cyclohexan-1,2-diol was the only by-product.

Table 5

Recycling of the catalytic phase by direct distilling of the cyclohexene oxide from the reaction medium, in the case of 3F03F.

\begin{tabular}{lllll}
\hline Solvent & Cycle & $\mathrm{TOF}_{0}\left(\mathrm{~h}^{-1}\right)^{\mathrm{a}}$ & Yield $(\%)^{\mathrm{b}}$ & Isolated $(\%)^{\mathrm{c}}$ \\
\hline $3 \mathrm{~F} 03 \mathrm{~F}$ & 1 & 95 & 73 & 78 \\
& 2 & 20 & 20 & 80 \\
& 3 & 14 & 8 & 85 \\
\hline
\end{tabular}

Conditions: 0.5 mol\% bis[3,5-bis(trifluoro-methyl)diphenyl] diselenide, 2 mmol of cyclohexene, $4 \mathrm{mmol} 50 \% \mathrm{H}_{2} \mathrm{O}_{2}, 2 \mathrm{~mL}$ solvent, $25^{\circ} \mathrm{C}$, 2h. After the first cycle, $4 \mathrm{mmol} 50 \% \mathrm{H}_{2} \mathrm{O}_{2}$ and $2 \mathrm{mmol}$ of cyclooctene were added.

${ }^{\text {a }} \mathrm{TOF}_{0}\left(\mathrm{~h}^{-1}\right)$, initial rate in mmol product $\mathrm{mmol}$ catalyst $\mathrm{t}^{-1} \cdot \mathrm{h}^{-1} \cdot{ }^{\mathrm{b}} \mathrm{GC}$-yield of epoxide, mmol cyclohexene oxide $\mathrm{mmol}$ cyclohexene $\mathrm{e}^{-1}$. $\mathrm{Pure}$ cyclohexene oxide obtained, $\mathrm{mmol}$ cyclohexene oxide isolated $\cdot \mathrm{mmol}$ cyclohexene oxide ${ }^{-1}$.

Table 6

Cyclohexene epoxidation in 3F03F, using different oxidant/olefin ratios.

\begin{tabular}{lllll}
\hline $\begin{array}{l}\text { Cyclohexene } \\
\text { (mmol) }\end{array}$ & $\begin{array}{l}\mathrm{H}_{2} \mathrm{O}_{2} / \text { Olefin } \\
\text { ratio }\end{array}$ & $\begin{array}{l}\mathrm{TOF}_{0} \\
\left(\mathrm{~h}^{-1}\right)^{\mathrm{a}}\end{array}$ & $\begin{array}{l}\text { Conv. } \\
(\%)^{\mathrm{b}}\end{array}$ & $\begin{array}{l}\text { Yield } \\
(\%)^{\mathrm{c}}\end{array}$ \\
\hline 4.53 & 1.9 & 235 & 96 & 45 \\
4.65 & 1.4 & 230 & 92 & 57 \\
4.45 & 0.9 & 200 & 79 & 71 \\
4.43 & 0.5 & 130 & 54 & 90 \\
\hline
\end{tabular}

Conditions: $0.5 \mathrm{~mol} \%$ bis[3,5-bis(trifluoro-methyl)diphenyl] diselenide, $2 \mathrm{mmol}$ of cyclohexene, $2 \mathrm{~mL}$ solvent, $25{ }^{\circ} \mathrm{C}, 2 \mathrm{~h}$.

${ }^{\mathrm{a}} \mathrm{TOF}_{0}\left(\mathrm{~h}^{-1}\right)$, initial rate in $\mathrm{mmol}$ product $\cdot \mathrm{mmol}$ catalyst ${ }^{-1} \cdot \mathrm{h}^{-1} \cdot{ }^{\mathrm{b}} \mathrm{GC}-$ conversión of olefine, mmol cyclohexene converted $\cdot \mathrm{mmol}$ cyclohexen $\mathrm{e}^{-1}$. $\mathrm{GC}-$ Yield over the theorical maximun of cyclohexene oxide, based on the quantity of oxidant, mmol cyclohexene oxide $\cdot \mathrm{mmol}$ oxidant $^{-1}$.

Table 7

Catalyst reuse in epoxidation of cyclohexene using hydrogen peroxide in water as oxidant and $3 \mathrm{~F} 03 \mathrm{~F}$ as solvent

\begin{tabular}{|c|c|c|c|c|c|}
\hline Cycle & $\begin{array}{l}\text { time } \\
(\mathrm{min})\end{array}$ & $\begin{array}{l}\mathrm{TOF}_{0} \\
\left(\mathrm{~h}^{-1}\right)^{\mathrm{a}}\end{array}$ & $\begin{array}{l}\text { Yield } \\
(\%)^{\mathrm{b}}\end{array}$ & $\mathrm{TON}^{\mathrm{c}}$ & $\begin{array}{l}\text { Diol } \\
(\%)^{\mathrm{d}}\end{array}$ \\
\hline \multirow[t]{3}{*}{1} & 5 & & 28 & 14 & 0 \\
\hline & 10 & 129 & 48 & 25 & 0 \\
\hline & 120 & & $>99$ & 54 & 0 \\
\hline \multicolumn{6}{|c|}{ Distillation of the product and recharging of fresh reagents for the second cycle } \\
\hline \multirow[t]{3}{*}{2} & 5 & & 31 & 84 & 0 \\
\hline & 10 & 88 & 52 & 91 & 0 \\
\hline & 120 & & $>99$ & 110 & 0 \\
\hline \multicolumn{6}{|c|}{ Distillation of the product and recharging of fresh reagents for the second cycle } \\
\hline \multirow[t]{3}{*}{3} & 5 & & 26 & 135 & 4 \\
\hline & 10 & 121 & 44 & 145 & 4 \\
\hline & 120 & & 76 & 155 & 15 \\
\hline
\end{tabular}

Conditions: $0.5 \mathrm{~mol} \%$ bis[3,5-bis(trifluoro-methyl)diphenyl] diselenide, 4 mmol of cyclohexene, $2 \mathrm{mmol} 50 \% \mathrm{H}_{2} \mathrm{O}_{2}, 2 \mathrm{~mL}$ solvent, $25^{\circ} \mathrm{C}$.

${ }^{\mathrm{a}} \mathrm{TOF}_{0}\left(\mathrm{~h}^{-1}\right)$, initial rate in mmol product $\cdot \mathrm{mmol}$ catalyst ${ }^{-1} \cdot \mathrm{h}^{-1} \cdot{ }^{\mathrm{b}} \mathrm{GC}-$ Yield over the theorical maximun of cyclohexene oxide, mmol cyclohexene oxide $\cdot m m o l$ oxidant. ${ }^{\mathrm{c}}$ Total turnover number mmol epoxide-mmol catalyst ${ }^{-1}$. ${ }^{\mathrm{d}}$ Cyclohexan-1,2-diol was the only by-product observed. 

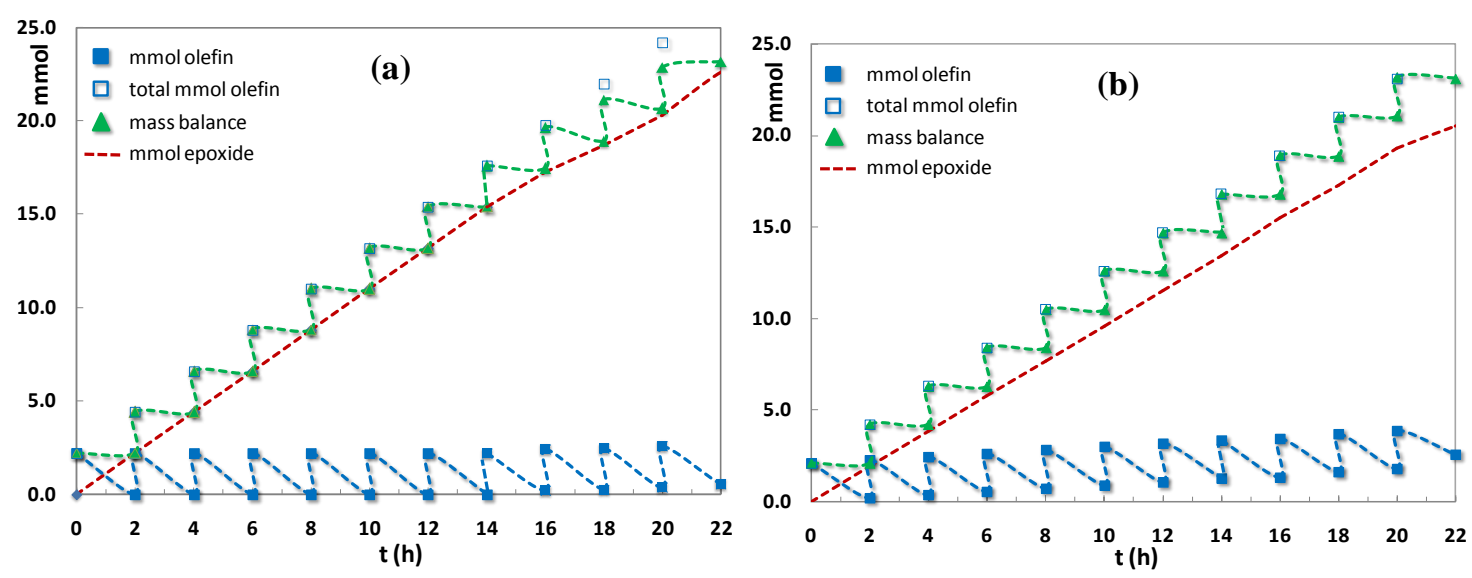

Fig. 1. Recharging fresh reagents in the epoxidation of cyclooctene with hydrogen peroxide using TFE (a) and $3 \mathrm{~F} 03 \mathrm{~F}$ (b) as solvents. Conditions: $0.5 \mathrm{~mol} \%$ bis[3,5-bis(trifluoro-methyl)diphenyl] diselenide, 2 mmol of cyclooctene, $4 \mathrm{mmol} 50 \%$ $\mathrm{H}_{2} \mathrm{O}_{2}, 2 \mathrm{~mL}$ solvent, $25{ }^{\circ} \mathrm{C}$. After $2 \mathrm{~h}$, when the reaction is completed, 4 mmol $50 \% \mathrm{H}_{2} \mathrm{O}_{2}$ and $2 \mathrm{mmol}$ of cyclooctene were added to run the next step. It was not carried out any distillation between steps.

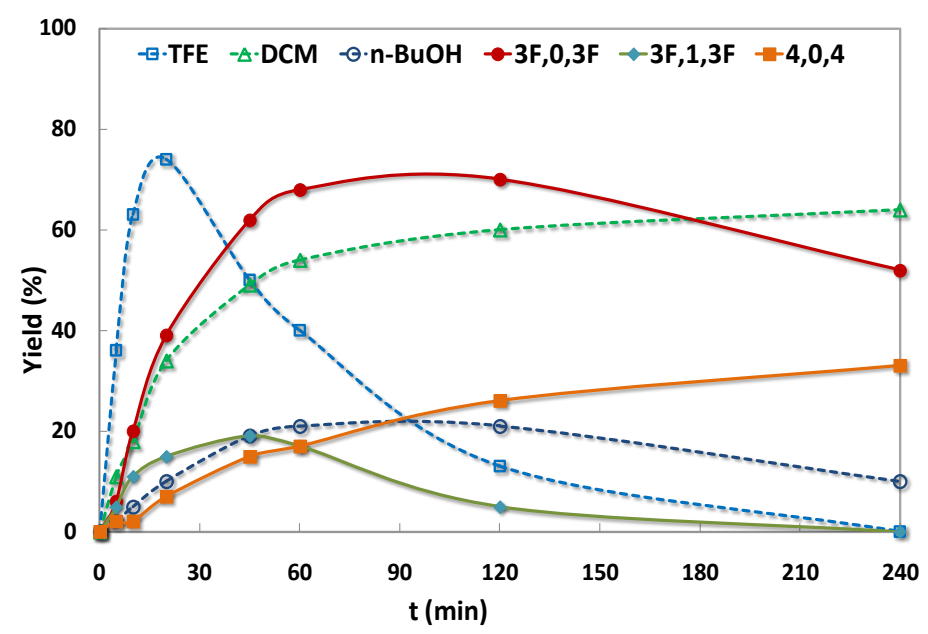

Fig. 2. Decay of cyclohexene oxide yield in time, due to hydrolysis in different solvents. The use of sodium acetate $(0.5$ mol\%) could solve that problem.

Conditions: $0.5 \mathrm{~mol} \%$ bis[3,5-bis(trifluoro-methyl)diphenyl] diselenide, 2 mmol of cyclohexene, $4 \mathrm{mmol} 50 \% \mathrm{H}_{2} \mathrm{O}_{2}, 2 \mathrm{~mL}$ solvent, $25^{\circ} \mathrm{C}, 4 \mathrm{~h}$.

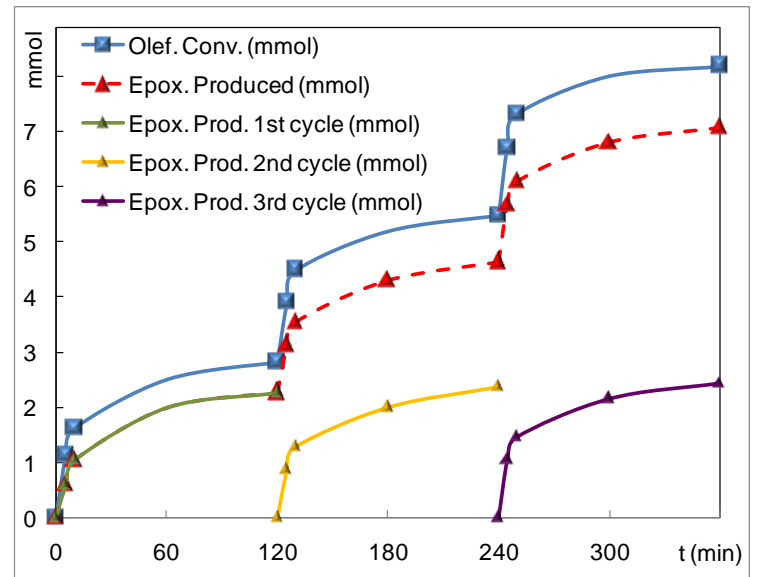

Fig. 3. Recovering of the catalysts by distillation of the product in the epoxidation of cyclohexene with hydrogen peroxide using $3 \mathrm{~F} 03 \mathrm{~F}$ as solvent. 
Conditions: 0.5 mol\% bis[3,5-bis(trifluoro-methyl)diphenyl] diselenide, 4 mmol of cyclohexene, 2 mmol 50\% $\mathrm{H}_{2} \mathrm{O}_{2}, 2 \mathrm{~mL}$ solvent, $25{ }^{\circ} \mathrm{C}$. After $2 \mathrm{~h}$, when the reaction is completed, cyclohexene oxide was removed by distillation and $2 \mathrm{mmol} 50 \%$ $\mathrm{H}_{2} \mathrm{O}_{2}$ and $4 \mathrm{mmol}$ of cyclooctene were added to run the next cycle.

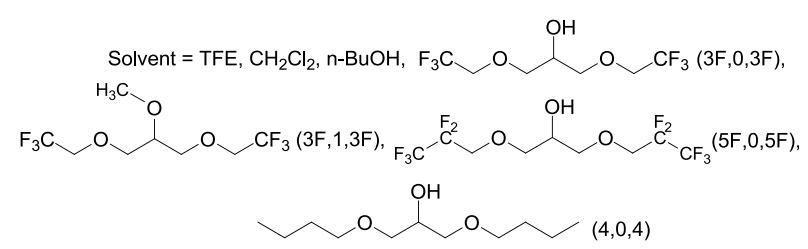

Scheme 1 Glycerol derivatives solvents used to carry out the epoxidation, they have been fully described previously [47].

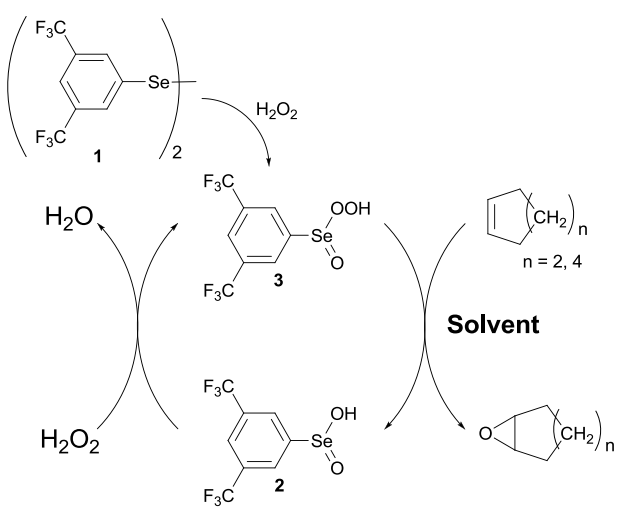

Scheme 2 Catalytic cycle proposed in the literature to explain the epoxidation cyclooctene and cyclohexene with arylseleninic acidhydrogen peroxide [21,25]. 


\section{Appendix A. Supplementary data}

Table S1

GC Conditions used to quantify results in olefins epoxidation reactions.

\begin{tabular}{|c|c|c|c|c|c|}
\hline Conditions & $\begin{array}{l}\mathrm{T}_{\mathrm{i}}^{\mathrm{a}} \\
\left({ }^{\circ} \mathrm{C}\right) \\
\end{array}$ & $\begin{array}{l}\mathrm{t}_{\mathrm{i}}^{\mathrm{b}} \\
(\min )\end{array}$ & $\begin{array}{l}\text { rate }^{\mathrm{c}} \\
\left({ }^{\circ} \mathrm{C} \cdot \mathrm{min}^{-1}\right)\end{array}$ & $\begin{array}{l}\mathrm{T}_{\mathrm{f}}^{\mathrm{d}} \\
\left({ }^{\circ} \mathrm{C}\right) \\
\end{array}$ & $\begin{array}{l}\mathrm{t}_{\mathrm{f}}^{\mathrm{e}} \\
(\min )\end{array}$ \\
\hline$\overline{P_{1}}$ & 80 & 1 & 25 & 230 & 8 \\
\hline $\mathrm{P}_{2}$ & 50 & 3 & 15 & 230 & 5 \\
\hline
\end{tabular}

Olefin conversion and olefin oxide yield were determined by area integration of gas chromatography peaks, following the calibration equations carried out with ethylene glycol dimethyl ether (glyme), which is used as an internal standard (Table S2).

(1)

\section{Table S2}

Calibrations lines used to quantify olefins (cyclooctene and cyclohexene) and epoxide (cyclooctene oxide and cyclohexene oxide).

\begin{tabular}{|c|c|c|c|c|c|c|c|c|}
\hline $\mathrm{R}$ or $\mathrm{P}$ & Conditions $^{\mathrm{a}}$ & Points $^{\mathrm{b}}$ & - & - & d & A & B & $\mathrm{R}^{2}$ \\
\hline cyclooctene & $\mathrm{P}_{1}$ & 5 & 0,3 & 2,1 & & 3,1163 & 0,09 & 0,9993 \\
\hline cyclooctene oxide & $\mathrm{P}_{1}$ & 5 & 0,2 & 1,2 & & 2,7774 & 0,08 & 0,9900 \\
\hline cyclohexene & $\mathrm{P}_{2}$ & 6 & 0,4 & 2,5 & & 2,3085 & $-0,07$ & 0,9997 \\
\hline cyclohexene oxide & $\mathrm{P}_{2}$ & 6 & 0,3 & 2,5 & & 2,2017 & $-0,03$ & 0.9995 \\
\hline
\end{tabular}

${ }^{a}$ See table 1. ${ }^{b}$ Number of samples (R or P and ethylene glycol dimethyl ether (glyme) as an internal standard) used to build up the calibration line. ${ }^{\mathrm{c}}$ Lower ratio between Reagent/Standard used in the line. ${ }^{\mathrm{d}}$ Higher ratio between Reagent/Standard used in the line. 